\title{
La (im)posibilidad del patrimonio: entre conflicto social y el lugar del Estado
}

\author{
The (im)possibility of heritage: between social conflict \\ and the place of the state
}

\author{
Yura Serrano-Via \\ FLACSO-Ecuador \\ yserrano@flacso.edu.ec \\ https://orcid.org/0000-0003-2515-5001 \\ Daniel Alejandro Vizuete-Sandoval \\ FLACSO-Ecuador \\ davizuete@flacso.edu.ec \\ https://orcid.org/0000-0003-2431-1746
}

\begin{abstract}
Resumen
Aproximarse a la gobernanza del patrimonio implica hacer un ejercicio de comprensión profunda de las dimensiones que intervienen allí: la distribución del poder, las prácticas culturales, la dimensión económica, imaginarios sociales y otros. En el presente trabajo se busca responder ¿qué factores posibilitan la gobernanza democrática de sitios con declaración patrimonial? A partir de la aplicación de la revisión bibliográfica y visitas de campo, se recolectó información que, desde de una estrategia cualitativa que combina observación estructurada y entrevistas, permitió analizar las particularidades y experiencias comunes en dos casos de gestión del patrimonio arqueológico en Ecuador: Ingapirca y Cerro de HojasJaboncillo. El procesamiento del conflicto social, las trayectorias institucionales y los procesos de apropiación patrimonial son elementos que conducen los hallazgos de este trabajo. La estrategia de indagación implicó el diseño de una herramienta metodológica y su aplicación en los dos sitios mencionados a 30 informantes locales de diferentes grupos sociales.
\end{abstract}

\section{Palabras clave}

Gobernanza, gestión patrimonial, arqueología en Ecuador, políticas culturales, conflicto social.

Forma sugerida de citar: Serrano-Via, Y., \& Vizuete-Sandoval, D.A (2020). La (im)posibilidad del patrimonio: entre conflicto social y el lugar del Estado. Universitas, 33, pp. 19-38. 


\begin{abstract}
Approaching heritage governance involves an exercise in deep understanding of the dimensions involved there: the distribution of power, cultural practices, the economic dimension, social imaginaries and others. In this work we seek to respond what factors enable the democratic governance of sites with heritage declarations? From the application of the bibliographic review and field visits, information was collected that, from a qualitative strategy that combines structured observation and interviews, allowed to analyze the particularities and common experiences in two cases of archaeological heritage management in Ecuador: Ingapirca and Cerro de Hojas-Jaboncillo. The processing of social conflict, institutional trajectories and heritage appropriation processes are elements that lead to the findings of this work. The inquiry strategy involved designing a methodological tool and its application on the two mentioned sites to 30 local informants from different social groups.
\end{abstract}

Keywords

Governance, heritage management, archeology in Ecuador, cultural policies, social conflict.

\title{
Introducción y estado de la cuestión
}

En los últimos años, se ha revitalizado la discusión sobre el patrimonio y su gestión tanto desde la investigación, como desde la administración pública (García, 2014). El planteamiento de agendas de investigación interdisciplinarias, nuevos enfoques u objetos analíticos, surgen precisamente de las inquietudes que nacen de las experiencias de la gestión y de los desafíos que la administración pública tiene por delante. Un aspecto recurrente en las discusiones, es el cuestionamiento que actores del ámbito de lo social como comunidades, pobladores y gestores locales hacen sobre los procesos de patrimonialización y el lugar que ocupan estos actores en dichos procesos. A escala global, la discusión se inscribe en los desafíos para promover una gobernanza democrática multinivel y para América Latina, además, se sitúa en el debate de la construcción del Estado plurinacional.

En Ecuador, la institucionalización de las políticas culturales ha sido un proceso tardío, interrumpido y conflictivo. Como muestra la creación, re- 
forma y desaparición de un sinnúmero de instituciones ligadas a la gestión patrimonial a lo largo del siglo XX. Desde la aprobación de la Ley de Patrimonio Artístico en 1945, hasta la creación del Instituto Nacional de Preservación Monumental (INPM) en 1970, pasaron más de 25 años para que se pueda generar la institucionalidad que promueva la implementación de la ley. Durante este periodo, la "política patrimonial" fue salvaguardar el patrimonio monumental.

Desde finales de los años setenta, se da un renovado impulso a la actividad arqueológica con la inclusión de contenidos en las universidades y la creación de una entidad especializada del Instituto Nacional de Patrimonio Cultural-INPC, en 1979 (Salazar, 1994), pero también por el financiamiento por bonanza petrolera y el mecenazgo. En adelante, los procesos de conservación, colección y exposición fueron realizados por entidades de diversa naturaleza como, la Casa de la Cultura, los museos municipales y universitarios y el Banco Central-BCE. Este último prevaleció en la gestión a lo largo de los ochenta y noventa debido a los recursos que destinó para la constitución y conservación de colecciones de objetos, lo que favoreció los intereses ligados al coleccionismo.

En la Asamblea Constituyente de 1997, se introduce el debate sobre la interculturalidad del país, concepto sobre el cual se generarán demandas de reconocimiento y autodeterminación de pueblos y nacionalidades y será fermento para procesos de apropiación de territorios, gobernanza y sitios de interés patrimonial. Fruto de un intenso ciclo de movilización social a inicios de los años dos mil empezaría a cristalizar en una propuesta política con raíces populares. En 2007, se inicia una reforma estatal y regulación de la vida social con la instalación de la Asamblea Nacional Constituyente. Aquí se revitalizaron las discusiones ligadas a la "interculturalidad" (Art. 21 de la CRE) y "derechos culturales" (Art. 377), la inclusión de la cultura en el régimen de desarrollo (Art. 276), la creación del Sistema Nacional de Cultura (Art. 340), entre otros.

El renovado interés del Estado en el tema patrimonial se evidencia no solo en la discusión constitucional, sino también con impulso a la institucionalidad del sector. La creación del Ministerio de Cultura en 2007, que supuso la apertura de un nuevo ciclo donde se realiza un desplazamiento conceptual de "patrimonio" a "cultura" lo cual modifica no solo las lógicas de gestión, sino también los debates existentes y por lo tanto, los actores involucrados. Durante este periodo se revitaliza también la discusión sobre las 
diferentes modalidades de la práctica arqueológica (Delgado, 2011).Aquí se retiraron atribuciones al Banco Central, se reformó en múltiples ocasiones el INPC, se crearon instrumentos como el programa de recuperación SOS Patrimonio y el Sistema de Información del Patrimonio Cultural EcuatorianoSIPCE. El fin de esta etapa y apertura de una nueva, ocurre con la aprobación de la Ley Orgánica de Cultura, en 2016, que busca articular el Sistema Nacional de Cultura y Patrimonio-SNCyP.

La presente investigación da cuenta de los hallazgos del trabajo de campo realizado en el marco del proyecto "Diseño e implementación del Sistema de Áreas Arqueológicas y Paleontológicas del Ecuador-SAAPE", ejecutado por la Facultad Latinoamericana de Ciencias Sociales -FLACSO- sede Ecuador y el Instituto Nacional de Patrimonio Cultural -INPC- entre junio de 2018 y diciembre de 2019. Uno de los objetivos del proyecto, fue construir un modelo de gestión para el naciente SAAPE, para lo cual se tomó como punto de partida la reflexión sobre las trayectorias de gestión patrimonial, el lugar del Estado y la gestión del conflicto, como factores que (im) posibilitan la gobernanza democrática del patrimonio.

En primer lugar, nos aproximamos al patrimonio desde una mirada relacional y, por tanto, reconocemos su dimensión conflictiva. Esta dimensión le otorga la posibilidad de ser constitutiva y ordenadora de (ciertas) relaciones sociales, las cuales deben ser abordadas como objetos analíticos a constatar en lugar de premisas de partida.

En segundo lugar, buscamos identificar el lugar que ocupan ciudadanos, organizaciones, poblaciones y comunidades en las experiencias de gestión patrimonial y dar cuenta del carácter performativo y cambiante de las instituciones y acuerdos existentes.

Las nociones de comunidad y territorio son el tercer elemento considerado en este trabajo, a partir de las cuales buscamos identificar los modos de relacionamiento, negociación y conflicto de las poblaciones involucradas o excluidas de la gestión patrimonial, con énfasis en los procesos de "valorización" del patrimonio.

Como cuarto elemento, subyacente a los anteriores, la tensión que se genera entre las piezas patrimoniales y la gestión del suelo. En Ecuador, el patrimonio es propiedad de todos los ecuatorianos y por ello, el Estado es su custodio; sin embargo, el patrimonio material existe en el suelo, que es gestionado desde la propiedad: privada, estatal, comunitaria, pero también des- 
de el ordenamiento territorial. Esta condición no solo habilita una disputa por las competencias entre los diferentes niveles de gobierno, sino también entre los propietarios del suelo y sus actividades.

El concepto de gobernanza, entonces, es orientador y transversal a esta reflexión. Como plantea Jessop la gobernanza "se refiere a mecanismos y estrategias de coordinación de cara a la interdependencia recíproca compleja entre agentes, organizaciones y sistemas funcionales operativamente autónomos" (2016, p. 230).

Esta visión implica un desbordamiento del Estado como única instancia capaz de ordenar el campo político - y específicamente para el caso patrimonial - y la entrada en escena de otros múltiples actores no estatales como el sector privado o la sociedad civil (Prats, 2004). En ese marco, una "gobernanza democrática" se corresponde con el tipo dialógica o de red explicada por el propio Jessop como la autoorganización reflexiva continua basada en redes, negociación y deliberación orientada hacia la definición y cambio de objetivos consensuados de largo plazo en donde además de la distribución del poder formal, intervienen prácticas y dinámicas sociales, económicas y culturales que desplazan dinámicas monológicas, monolíticas y jerárquicas por procesos "dialógicos, plurales y heterárquicos" (Jessop, 2016).

\section{Materiales y métodos}

Para el análisis, la recopilación de información y el contraste de la misma respecto a la interrogante en torno a los factores que posibilitan (o no) una gobernanza democrática del patrimonio; en el presente trabajo se desarrolló una herramienta teórico-analítica que de cuenta de cuatro dimensiones específicas que intervienen en el proceso de gobernanza en los términos en que se ha definido a la misma. El poder, las prácticas culturales, los circuitos económicos y la memoria e imaginarios son las dimensiones de análisis que fueron abordadas desde una doble estrategia metodológica: por un lado, la etnografía aplicada en las salidas de campo a cada lugar (observación y entrevistas) y, por otra parte, la revisión bibliográfica relacionada a la discusión y los casos.

De manera específica, la herramienta busca dar soporte a la técnica de observación estructurada. Este enfoque se emplea para identificar las for- 
mas y mecanismos más perceptibles de interacción social y de los conflictos que esta genera (Ragin, 2007). Además, brinda la posibilidad de aproximación al entendimiento de los vínculos considerándolos efecto de una negociación permanente entre los grupos sociales y lo que se puede definir como sus patrimonios. La observación permite complementar el uso de diferentes medios, como diarios de campo, cuadros de trabajo y cuestionarios, pero su aporte fundamental reside en la capacidad de interactuar con actores en tiempo presente e ir más allá de la información directamente reportada por los actores (Echeverría, 2011).

En el presente artículo interesa evidenciar la elaboración y estructura de la herramienta teórico-analítica por sobre los propios hallazgos fruto de la aplicación de la misma con el objeto de reflejar el componente investigativo del proyecto FLACSO-INPC. En ese sentido, las dimensiones analíticas son el resultado de la discusión interdisciplinaria interna y la revisión teórica. Posteriormente se trabajó en la construcción de interrogantes guía, la selección de los casos y la aplicación de herramientas.

Así, se define a las dimensiones como:

Poder: Se busca dar cuenta del campo de fuerzas constituido por relaciones sociales entre actores con posición diferencial, desigual y jerárquicamente articulada en un orden social y orientada hacia un horizonte colectivo, donde un actor o conjunto de actores logran imponer su voluntad a pesar de las resistencias de otros. (Weber, 2005). Es indispensable pensar los segmentos sociales que se articulan, el modo en que lo hacen, qué funciones diferenciales cumplen, qué jerarquías atraviesan a sus integrantes y cómo su desigualdad redunda en acceso diferencial a los bienes socialmente producidos o su capacidad de participar del campo político. El poder es posible observar en instituciones estatales de diversos niveles, instituciones sociales o a través del control de recursos (Weber, 2007).

Prácticas culturales: Se aborda el patrimonio y sus prácticas asociadas, como un campo que produce significados y sentidos para los procesos de memoria e identidad (Kingman, 2004), en los que se articulan materialidades específicas y prácticas culturales, a unas esferas de construcción de sentidos públicos. Las prácticas culturales se observan en los procesos de patrimonialización de objetos, ritos o costumbres a las cuales se les asigna valor tanto desde el Estado por medio de declaratorias, como desde la ciudadanía a través de apropiaciones y usos en la cotidianeidad lo cual hace que el pa- 
trimonio "exista" más allá de la "oficialidad estatal". Los objetos y las prácticas culturales corresponden a las esferas del mundo de la vida y la experiencia cotidiana y que, al insertarse por vía de declaratorias y de su puesta en valor en los circuitos patrimoniales, transforman sus sentidos. A partir de ello, podemos identificar dos niveles: como factor de cohesión social basado en la activación de la identidad, y como elemento potenciador de los procesos de desarrollo local a través de oportunidades en la economía basada en los usos, apropiaciones, valoraciones y disfrute de esos patrimonios.

Circuitos económicos: Se observa la división del trabajo, flujos, circuitos e interconexión jerárquica de territorios atravesados por dinámicas sociales de producción, circulación y acumulación de bienes y valores sociales (Granovetter, 1977). Para la presente investigación interesa preguntarse respecto al lugar que ocupa el patrimonio en la producción, intercambio y consumo en los contextos territoriales respectivos donde son ordenadas y caracterizadas (Polanyi, 1975). Dar cuenta de las normas e instituciones económicas existentes permitirá evidenciar el horizonte de desarrollo en términos de satisfacción material de condiciones de vida, producción de valor de cambio a través del patrimonio y distribución de riqueza de los habitantes cercanos a sitios patrimoniales.

Memoria e imaginarios: Da cuenta de las trayectorias de los procesos de identidad, intercambio, acumulación simbólica y proyección de las aspiraciones sociales y su relación con los procesos de patrimonialización (Ariño, 2002). En contextos de desigualdad, las poblaciones están constantemente movilizando dispositivos de consenso, sean objetos materiales, monumentales o artefactos, prácticas o rituales, en la esfera pública no sólo para fines de cohesión social y construcción identitaria, sino como criterios de audibilidad, legitimidad e inclusión étnica y socioeconómica. En esta perspectiva el ejercicio de los derechos culturales implica no solamente el acceso y disfrute de los patrimonios, sino la posibilidad de apropiación, transformación y acrecentamiento desde usos sociales concretos. El patrimonio, entonces, opera como un ordenador de las versiones dominantes del pasado como sustrato identitario, forma hegemónica de selección de la memoria y recurso del desarrollo (Durán, 2014). 


\section{Interrogantes marco de la herramienta}

\section{Tabla 1 \\ Interrogantes por dimensión}

\begin{tabular}{|c|c|}
\hline Dimensión & Interrogante orientadora \\
\hline \multirow{2}{*}{ Poder } & $\begin{array}{l}\text { ¿De qué manera se organiza y distribuye el poder en el lugar con relación al lugar } \\
\text { arqueológico? }\end{array}$ \\
\hline & $\begin{array}{l}\text { ¿Cómo participan los distintos actores estatales y sociales en la toma de decisiones } \\
\text { y organización del lugar arqueológico? }\end{array}$ \\
\hline \multirow{3}{*}{$\begin{array}{l}\text { Prácticas } \\
\text { culturales }\end{array}$} & $\begin{array}{l}\text { ¿De qué manera incide el proceso de patrimonialización de un lugar arqueológico } \\
\text { en las dinámicas sociales? }\end{array}$ \\
\hline & ¿En qué medida el proceso de patrimonialización es un factor de cohesión social? \\
\hline & $\begin{array}{l}\text { ¿De qué manera participan los actores sociales, conocen, valoran, producen y } \\
\text { acceden a sus patrimonios arqueológicos o los articulan a otros patrimonios locales? }\end{array}$ \\
\hline \multirow{3}{*}{$\begin{array}{l}\text { Circuitos } \\
\text { económicos }\end{array}$} & $\begin{array}{l}\text { ¿Qué actividades/actores participan de la acumulación material y simbólica con } \\
\text { relación al lugar arqueológico? }\end{array}$ \\
\hline & $\begin{array}{l}\text { ¿Cómo imaginan los actores sociales su relación con lo arqueológico en términos de } \\
\text { imaginarios de "desarrollo"? }\end{array}$ \\
\hline & $\begin{array}{l}\text { ¿Es posible identificar procesos de desigualdad, exclusión o desapropiación en torno } \\
\text { a los lugares arqueológicos? }\end{array}$ \\
\hline \multirow{3}{*}{$\begin{array}{l}\text { Memoria } \\
\text { e imaginarios }\end{array}$} & ¿De qué manera los actores sociales ejercen su derecho al patrimonio? \\
\hline & $\begin{array}{l}\text { ¿Cómo definen su identidad comunitaria y territorial y de qué manera esta incorpora } \\
\text { lo arqueológico? }\end{array}$ \\
\hline & $\begin{array}{l}\text { ¿Existen límites temporales en los procesos de patrimonialización que inciden en los } \\
\text { imaginarios de los actores sociales? }\end{array}$ \\
\hline
\end{tabular}

\section{Casos seleccionados}

La selección de los casos en donde se aplicó la herramienta estuvo determinada por:

- La identificación de sitios con declaratoria patrimonial con trayectorias de gestión diversas lideradas por el Estado.

- La ponderación de procesos de conflicto social, político e institucional ligados a la gestión del patrimonio. 
- El acervo previo de investigaciones y excavaciones de tipo arqueológico.

- El interés de la contraparte institucional en ampliar el conocimiento sobre los contextos de sitios con declaratoria patrimonial.

\section{Aplicación de la herramienta}

La observación estructurada y las entrevistas fueron realizadas según el siguiente detalle:

Tabla 2

Detalle de entrevistas por sitio patrimonial

\begin{tabular}{|c|c|c|c|}
\hline Sitio Patrimonial & Cantones & Entrevistas & $\begin{array}{c}\text { Tipo de actor } \\
\text { y número de entrevistado }\end{array}$ \\
\hline \multirow{3}{*}{$\begin{array}{l}\text { Cerro de Hojas } \\
\text { Jaboncillo }\end{array}$} & \multirow{3}{*}{ Portoviejo } & \multirow{3}{*}{15} & Institucional (7) \\
\hline & & & Sociedad civil/comunidad (4) \\
\hline & & & Privado (4) \\
\hline \multirow{3}{*}{ Ingapirca } & \multirow{3}{*}{$\begin{array}{l}\text { Cañar, Tambo } \\
\text { y Cuenca }\end{array}$} & \multirow{3}{*}{13} & Institucional (6) \\
\hline & & & Sociedad civil/comunidad (3) \\
\hline & & & Privado (4) \\
\hline
\end{tabular}

\section{Análisis y resultados}

\section{Caso Ingapirca}

\section{Poder}

En términos de la distribución del poder, un primer factor es el alto grado de conflictividad social acarreado por tensiones de orden étnico en los territorios donde se ubican los hallazgos: "es difícil para manejar juntos los indios y mestizos porque tienen aspiraciones diferentes y por el racismo" (Erspamer, 2010 , p. 20). Esto se explica, en parte, por herencia de la larga trayectoria de la colonia y su dinámica de dominación y producción que se ha ido fraccionan- 
do progresivamente con el paso del tiempo. Un segundo factor es el agresivo proceso migratorio iniciado tempranamente en la década de los noventa y sus implicaciones económicas y generacionales (Velecela, 2015).

A nivel institucional, Ingapirca estuvo administrado por varias comisiones cívicas, conocidas como "Comisión del Castillo" dependientes del Banco Central del Ecuador entre 1966 y 1985. Fruto de la discusión de la constitución de 1998, ocurriría un giro importante en el modo de gestión. En 2001 se crea el Instituto Ingapirca del Pueblo Kañari-IIPK, con la misión de gestionar el sitio por sus "legítimos propietarios" en un contexto de intensa movilización y apropiación (simbólica y material) del sector indígena conectado con los procesos que sucedían a escala nacional (Erspamer, 2010). Para un ex funcionario del sitio (entrevista personal, 2019), esta nueva forma de gestión generó tensiones con los habitantes mestizos, quienes desde la Junta Parroquial presionarían por la salida de la administración indígena. En 2005, mediante una toma del sitio, ocurriría finalmente la expulsión de dicho mecanismo de gestión (IIPK) y se encarga la gestión al INPC, que estaría condicionada por la Junta Parroquial local. En 2010 se deroga la existencia del IIPK y se traslada la gestión al INPC que apenas en 2016, por acción de la LOC, asume plenamente el sitio como "Centro Arqueológico Ingapirca" -CAI- (INPC, 2011).

Los principales espacios de influencia social y política son la Junta Parroquial, el Municipio de Cañar, la oficina zonal y la Planta Central del INPC, los negocios circundantes al CAI y liderazgos de las comunidades (en especial Sisid y Cahuanapamba). Se evidencia un debilitamiento de la presión del sector indígena-comunero - que se corresponde además con la situación que atraviesan organizaciones históricas como la TUCAYTA o la UPCCC (Martínez, 2003) - que no encuentra confluencia en los intereses de los distintos espacios articulados. Es preciso mencionar que no existen mecanismos consultivos, deliberativos o democráticos que permitan fijar acuerdos de gobernanza y un horizonte común entre los distintos actores de la localidad respecto a la gestión del sitio como lo plantea Velecela (2015, p. 97). La centralidad en el manejo del Complejo Arqueológico y la latente tensión con la Junta Parroquial y las comunidades aledañas, como detallan los propios pobladores, hacen que se dificulte entablar una dinámica virtuosa para la gestión sitio.

\section{Prácticas culturales}

El Complejo Arqueológico fue utilizado por varias décadas para reivindicar y celebrar festividades como el Inti Raymi y otras ligadas a la tradición 
indígena - sobre todo a partir del proceso de patrimonialización en la década de los setenta - . Las comunidades de la zona "tomaban" el lugar para poner en escena su ritualidad y en ella confluían sectores mestizos del centro parroquial urbano. Como lo reconocen varios de los actores entrevistados (funcionarios CAI, autoridades parroquiales y comerciantes) este era el momento de mayor exposición de las comunidades como del propio sitio. Así mismo, la organización de estas actividades generaba que los distintos sectores converjan, pero, dadas las tensiones de los últimos años por la disputa en la administración del lugar, la celebración de las fiestas se desplazó a otro lugar (Guantug-Cañar). Así, se identifica un desplazamiento en el ejercicio de prácticas e intercambios que posibilitaban la cohesión social por una utilización de las mismas para evidenciar el conflicto interno.

Si bien el proceso de patrimonialización de los bienes y hallazgos arqueológicos a lo largo del tiempo ha legitimado una reivindicación identitaria (indígena Cañari), y unas prácticas ancestrales (ritualidad festiva); es posible percibir también un uso estratégico de estos elementos. Es decir, una activación específica, temporal y situada de ese ethos y no como una cuestión orgánicamente asimilada de la dinámica cultural. A la interrogante respecto al uso de vestimenta o de otras prácticas ancestrales más allá de las festivas las respuestas de los entrevistados no fue detallada.

\section{Circuitos económicos}

La estructura económico-productiva de la localidad y los circuitos económicos ligados (y no) al patrimonio arqueológico requieren de una mirada articulada. Por un lado, el territorio donde se ubica el Complejo Arqueológico es eminentemente rural. La actividad que por muchos años generaba ingresos a los pobladores fue la agricultura que, progresivamente, fue complementándose y en casos desplazada por la ganadera para la producción y comercio de leche (Velecela, 2015). Sin embargo, si algo cambió radicalmente la situación económica (y social) del lugar fue la inyección de remesas por parte de los familiares que emigraron al exterior: mayor dinero circulante en la localidad, acceso a bienes y, en menor medida, factores de producción. Hasta donde se indagó, fue muy discreta la inversión realizada de esta fuente en la actividad económica alrededor del patrimonio arqueológico (algunos casos de hospedaje).

Lo que respecta a las actividades económicas vinculadas a la circulación de visitantes y turistas al complejo arqueológico se puede sostener que es 
aún muy puntual, limitada y carente de ampliación de oferta tal como lo describen las propias autoridades locales y pobladores dedicados a la actividad turística (entrevistas personales, 2019). Existen varios negocios privados ligados al sitio (hospedaje y alimentación) que representan casi en exclusiva la oferta local. Por fuera de estos y del personal que trabaja en el CAI, no existen otras fuentes de empleo remunerado vinculadas a la actividad patrimonial arqueológica de Ingapirca. La visita de turistas al sitio está determinada en gran medida por las redes y agendas de operadoras turísticas domiciliadas en Cuenca, Quito o Guayaquil.

\section{Memoria e imaginarios}

Ingapirca - y el cantón Cañar en su conjunto- constituye hasta el día de hoy un territorio de intensa y compleja reafirmación identitaria. En este sentido, el patrimonio arqueológico ha sido utilizado para legitimar la escalada de un relato de identidad, lucha y reivindicación indígena. En este proceso, ha existido y existen casos de comunidades que han articulado esta forma de mirarse con demandas y acciones concretas en la esfera de lo público (no sucede lo mismo en todas las comunidades que conforman la parroquia). Por ejemplo, las comunidades de Sisid y Cahuanapamba, según explica el líder local, Felipe Chimborazo (entrevista personal, 2019) reclaman el derecho a gestionar no solo Ingapirca, sino también los sitios de $\mathrm{Cu}-$ lebrillas y Paredones. Sitios, estos, de la cultura Cañari que forman parte del Qhapac Ñan. Se evidencian casos allí de un grado de formación de memorias e imaginarios más elaborado que no se limita a la disputa exclusiva del complejo Ingapirca.

Al indagar sobre la noción e imaginario de "desarrollo" presente en la localidad, quizá el único consenso existente entre los diferentes actores es que el CAI - en condiciones distintas - puede ser un motor que genere desarrollo para la localidad. Esto desde una mirada tanto productivo-económica cuanto institucional. Existen particularidades desde las que cada actor manifiesta una mirada específica de cómo debería ser orientada una perspectiva de bienestar y mejoramiento/cambio de la situación local: para los funcionarios del complejo arqueológico esta posibilidad pasa por la disminución de la conflictividad entre los distintos actores; la dotación de infraestructura turística en el sector y; una mejor disposición de los recursos captados por ingreso al sitio. Para las comunidades, es la posibilidad de distribución de los ingresos percibidos por la administración del CAI en la lo- 
calidad y la posibilidad de ampliar o al menos rotar las plazas de empleo que da el CAI (guías).

Para los habitantes del centro urbano, el "desarrollo" pasa por la ampliación del flujo de turistas y la condición de que estos dejen más divisas en el sitio. Existe el malestar de que los grandes flujos de turistas internacionales gestionados por operadoras de Cuenca, Quito o Guayaquil no incentivan el comercio local, por lo cual están planteando una conexión más estrecha entre el sitio y el centro urbano que motive el consumo y circulación de divisas en el centro.

\section{Caso Cerro de Hojas-Jaboncillo}

\section{Poder}

"Cerro de Hojas-Jaboncillo" es un sitio patrimonial ubicado en el macizo montañoso de la costera provincia de Manabí. La importancia patrimonial de este sitio está vinculada a la "sociedad prehispánica que habitó los cerros Hojas y Jaboncillo, identificada como parte de la cultura Manteña" (INPC, s/a). En 2009, a consecuencia del interés manifestado por la Asamblea Nacional Constituyente, el gobierno declara al macizo montañoso como Parque Arqueológico, dando cuenta de "una nueva política estatal que quiso reconocer la importancia cultural del patrimonio precolombino" (Lunnis, 2011, p. 147). Esta declaratoria supuso el inicio de un proyecto que buscó determinar el estado de conservación de las estructuras ubicadas en el complejo y la recuperación del patrimonio en términos de conservación, producción de conocimiento, creación de circuitos turísticos que permitan el acceso y disfrute de la ciudadanía ("puesta en valor") y constituir un estímulo para la economía local. Una vez culminado el proyecto de rescate, dirigido desde la Corporación Ciudad Alfaro desde 2009, y por disposición de la Ley Orgánica de Cultura aprobada en 2016, el Complejo Cerro de Hojas Jaboncillo fue trasladado a la administración del INPC.

Los informantes institucionales, sociales y privados (entrevistas personales, 2018) coincidieron en señalar como relevantes para las decisiones políticas a los propietarios de comercios locales, empresarios mineros (canteras), dirigentes cívicos articulados en la "Junta Cívica". Sin embargo, existen diferencias en la percepción sobre la incidencia de una emergente 
cohorte de liderazgos jóvenes cuya base de apoyo es la representación barrial y funcionarios públicos de larga trayectoria en los ámbitos de la salud y educación. Las diferencias generacionales de los líderes políticos se evidencian tanto en los cuestionamientos o apoyos que se realizan a figuras tradicionales en el seno de las mismas organizaciones, como en lo referente al aparecimiento de nuevas formas de acción colectiva como las barras organizadas. Según el testimonio de una guía del sitio "los jóvenes están más preocupados de las barras de fútbol, que de la junta cívica o de los barrios" (Entrevista personal, 2018).

\section{Circuitos económicos}

En relación al sitio, la intervención de "Ciudad Alfaro" supuso la delimitación del área de conservación, la construcción de infraestructura administrativa, museológica y de investigación. Este proceso supuso una fuerte implantación del Estado central como actor con capacidad de decisión que, según varios guías "supuso que la gente se aleje del sitio" (entrevista personal, 2018). Ello supuso el cambio de varios vínculos económicos: los habitantes locales que se vincularon subordinadamente al trabajo de investigación, guianza o administración del sitio ganaron prestigio mientras que pobladores que estaban acostumbrados a usar las inmediaciones del sitio para actividades agrícolas y de crianza de animales, o actividades lucrativas como la búsqueda y venta de piezas arqueológicas o tours guiados al macizo se consideraron agraviados por su abrupta exclusión (entrevista personal, 2018). La mayor parte de los pobladores de Picoazá se dedican a actividades comerciales, los principales espacios son los expendios de comida ubicados en las inmediaciones del parque central, la venta de artículos de hogar o ropa en las calles y almacenes. Las personas que no realizan sus actividades económicas en Picoazá normalmente se desplazan a Portoviejo para realizar ventas ambulantes de dulces, bebidas y lotería (Entrevista personal, 2018).

La relevancia económica del Parque Arqueológico, es marginal y poco determinante en la localidad. Varias han sido las iniciativas de la propia administración del parque por generar actividades conexas a la visita y uso de las instalaciones como artesanías realizadas por pobladores o pequeños productos naturales; sin embargo, no ha terminado por cristalizar el interés de la población en ello dado que no es una fuente segura de ingresos (salvo por la guianza). Existe la expectativa de que el sitio funcione como una atracción turística generadora de empleo local, sin embargo, no se identifica la 
iniciativa privada que dinamice esta actividad: no se reportaron operadoras privadas de circuitos turísticos ni infraestructura hotelera (privada o comunitaria) que pueda dar soporte.

\section{Prácticas culturales}

La cotidianidad de Picoazá está marcada por las actividades ligadas al comercio y prácticas religiosas de matriz católica. Especialmente relevante es la fiesta de San Pedro y San Pablo, celebrada en junio de cada año. Este evento es una puesta en escena del encuentro de dos sociedades, negros y blancos respectivamente, donde, por cuenta de los priostes se convida alimentación, licor y espectáculos musicales a los asistentes. Por otra parte, la devoción por la "Virgen María de la Asunción" se expresa a cada paso. En la parroquia existen numerosas capillas o grafitis que la representan, construidas en base a la iniciativa de personas interesadas que ganan prestigio en la parroquia por su gestión. Según un funcionario del sitio "la gente tiene más presente a la virgen, que a la historia de los abuelos manteños, por eso no vienen acá (al parque)" (Entrevista personal, 2018). El deporte también ocupa un lugar importante en la vida pública de la parroquia: los jóvenes se organizan principalmente en barras bravas de equipos nacionales y apoyan a equipos de fútbol locales, como el San Pedro

\section{Memoria e imaginarios}

El proceso de patrimonialización de los hallazgos arqueológicos del cerro no ha influido de manera determinante en las dinámicas sociales internas de la localidad ni en sus prácticas culturales. El uso del cerro, por lo que se pudo reconocer, no tiene un vínculo directo con el bien arqueológico: antes de las excavaciones, la comunidad llegaba al lugar con otros fines mas no para una reivindicación identitaria en referencia a una cultura ancestral. Según un habitante de la localidad "desde que llegó el gobierno nos quedamos sin parque y los chicos sin monte para jugar" (Entrevista personal, 2018). Por ello, no se puede reconocer que el bien arqueológico patrimonializado influya de alguna manera directa en la cohesión social interna.

Existen varios procesos identitarios que coexisten entre sí. La matriz católica, fuertemente arraigada y recreada mediante la festividad de San Pedro y San Pablo o la devoción a la Virgen de la Asunción son muestra de ello. Sin embargo, el discurso de pertenencia a la cultura Manteña ha sido revita- 
lizado desde la creación del Centro: "desde que tenemos el museo sabemos que hacían nuestros abuelos" sostuvo una guía (Entrevista personal, 2018). Los imaginarios del sitio han sido influenciados, también, por las prácticas ligadas a la excavación arqueológica. Ciertas personas se incorporaron a los circuitos de coleccionismo mediante el huaquerismo, imaginario que se comenzaría a valorar negativamente a partir de la acción del Centro de Interpretación del Parque. Por su parte, los funcionarios proyectan un imaginario del sitio como fuente de memoria local y nacional basada en la investigación arqueológica, lo cual demanda de la población local, la subordinación de su conocimiento local a los intereses de los investigadores o su participación en actividades asociadas al funcionamiento del sitio, en términos de provisión de alimentos, servicios, entretenimiento o artesanías.

\section{Discusión y conclusiones}

En primer lugar, se puede concluir, a través de los casos revisados, que un aspecto determinante para posibilitar una gobernanza democrática del patrimonio es el reconocimiento y procesamiento de la conflictividad social - que no significa su anulación - . Esta no puede ser invisibilizada desde una perspectiva de inmovilismo institucional, ni ser omitida en cualquier iniciativa que busque mejorar la gestión y toma de decisiones en estos sitios de una manera dialógica, pluralista y heterárquica como lo plantea Jessop (2016). Segundo, la conflictividad, a su vez, no puede ser reducida a un carácter exclusivamente étnico, ya que en los sitios patrimoniales también se manifiestan aquellos de clase u otros menos visibles como los de género. Estos representan un desafío directo tanto para la investigación de las dinámicas de los sitios como para la formulación de procesos de gobernanza. Por otra parte, cabe comprender al proceso de patrimonialización también con un carácter conflictivo: ¿quién determina qué es patrimonio y qué no? ¿qué identidades, prácticas e imaginarios se están legitimando con ello? ¿qué ocurre con las reivindicaciones propias de las comunidades y territorios que no alcanzan a ser reconocidas desde las instituciones? son algunas de las interrogantes que invitan a complejizar la mirada en este sentido.

A través del caso de Cerro de Hojas-Jaboncillo, resulta evidente que no es suficiente con garantizar la sostenibilidad y dotación de infraestructura a través del Estado como promotor exclusivo de procesos de patrimonializa- 
ción, para asegurar la gobernanza democrática de los sitios patrimoniales. El despliegue institucional, los recursos movilizados, la infraestructura generada no ha sido suficiente para intensificar los vínculos de una población - como la de Picoazá - con los hallazgos, bienes y discursos oficiales del patrimonio identificado allí.

Este caso también invita a pensar cómo la vigencia del imaginario del habitante local asociado al folclor (aún persistente), la debilidad de las organizaciones civiles y la dispersión de la acción colectiva, la articulación de circuitos económicos basados en empleos precarios o mal remunerados y la vitalidad de prácticas asociadas al deporte y la religiosidad abonan el camino para que la población local se distancie material, simbólica y políticamente del sitio, dificultando su participación en las actividades cotidianas y el ejercicio pleno de sus derechos culturales. Esto da cuenta que no se trata de "poco interés" de la población por su vínculo con ese patrimonio, sino que los procesos de apropiación exceden los problemas de sostenibilidad, infraestructura y promoción de la actividad arqueológica del sitio. Es un llamado para la problematización de la política patrimonial y cultural y los modos en que esta se aplica en diversos contextos. ¿Se puede ejercer gobernanza democrática en estos escenarios?

La experiencia de gestión del patrimonio arqueológico de Ingapirca, por otra parte, constituye un punto crucial para la comprensión del lugar del conflicto social en la gestión del patrimonio. Aspectos de orden étnico ponen sobre la mesa, justamente, que los procesos de patrimonialización no son una cuestión neutral y que más bien los acumulados históricos de exclusión pueden ser profundizados desde una perspectiva vertical y únicamente institucional. Facilitar el procesamiento del conflicto social latente allí pasa también por democratizar las instancias de gestión y deliberación respecto a éste y otros complejos arqueológicos. La institucionalidad vigente debe facultar el reconocimiento de formas de organización diferenciadas para la gestión de sitios y bienes patrimoniales que presentan condiciones como las expuestas en Ingapirca. Lo anterior no implica que "resolver" el problema de la administración del sitio, resuelve la tensión propia del lugar. Lo que sugiere es que en lugar de respuestas institucionales que apuntan a concentrar la gestión e invisibilizar el conflicto, se requiere desplegar mecanismos que utilicen al Complejo como posibilidad de acuerdo y confluencia antes que de disputa. El caso invita a complejizar las respuestas a nivel central en términos de modos de gestión del patrimonio más allá de figuras estandari- 
zadas y lineales (monológicas y monolíticas) que no reconocen las tensiones sociales.

En el caso del patrimonio material se da una particularidad. El Estado ecuatoriano reconoce: la propiedad comunitaria, pública y privada de la tierra, competencias por nivel de gobierno y la propiedad pública de piezas y vestigios patrimoniales. Distante a ser una controversia jurídica por la propiedad, esta concurrencia de procesos genera tensiones, sobre todo por las diversas trayectorias y perspectivas que conviven en la gestión patrimonial, por lo que se requiere la constatación empírica, caso por caso, del modo en que se expresan y negocian los conflictos, articulan los intereses, destinan recursos y deciden aspectos relevantes en cada sitio. No es posible llevar adelante una gestión democrática del patrimonio sin contemplar la gestión del suelo. A su vez, tampoco la gestión del suelo para otros fines puede obviar al patrimonio como un elemento relevante en la vida de las poblaciones. Por esto, la gestión patrimonial requiere la aceptación mutua entre los actores involucrados para buscar soluciones a situaciones como la de Ingapirca, donde las comunidades demandan la administración del sitio al ser propietarios de las tierras, o Jaboncillo, donde el polígono patrimonial es amenazado por minería pétrea realizada en las inmediaciones del macizo.

El proceso de construcción y aplicación de la herramienta analítico-metodológica para el trabajo de campo deja varias lecciones como la necesidad de aproximarse a las experiencias de gestión patrimonial desde un enfoque complejo que combine varias dimensiones analíticas y sea capaz de captar los testimonios de informantes pertenecientes a diversos grupos socialmente relevantes en la vida de los sitios. La diversidad en las fuentes permite la confrontación de versiones como ejercicio de triangulación. El número de informantes al igual que las condiciones en las que se aplican las entrevistas deben ser controladas y observadas detenidamente.

\section{Apoyos y agradecimientos}

A Valeria Coronel, Francisco Salazar, Daniela Balanzátegui, Lucía Durán, Christian Pino y José Marrero, miembros del proyecto FLACSO-INPC por los valiosos intercambios durante su desarrollo. 


\section{Bibliografía}

Ariño, A. (2002) La patrimonialización de la cultura y sus paradojas en la sociedad del riesgo. En J.M. García Blanco, y P. Navarro (Eds.), ¿Más allá de la modernidad? Las dimensiones de la información, la comunicación y sus nuevas tecnologías (pp. 329-350). Centro de Investigaciones Sociológicas.

Delgado, F. (2011). La arqueología ecuatoriana en el siglo XXI: entre la academia y la Arqueología Aplicada. En K. Enríquez (Ed.), La arqueología y la antropología en Ecuador (pp. 17-40). Corporación Editora Nacional.

Durán, L. (2014). La Ronda: olvidar el barrio, recordar la calle. Quito

Echeverría, J. (2011). Glosario de Arqueología y temas afines (Tomo I). Instituto Nacional de Patrimonio Cultural.

Erspamer, B. (2010). La Arqueología en el Ecuador: Investigando las Lecciones del Pasado y las Cuestiones del Presente. Independent Study Project (ISP) Collection. 976. https://bit.ly/3a30z5K

García, Z. (2014). Espacios que construyen ciudadanía: La educación patrimonial en la gestión del patrimonio cultural desde América Latina. Revista América Patrimonio, 13, 172-180. https://bit.ly/2DFnzfa

Granovetter, M. (1977) The strength of weak ties. In Social networks (pp. 347-367). Elsevier.

Instituto Nacional de Patrimonio Cultural (2011). "Plan de gestión integral para la conservación y puesta en valor del Complejo Arqueológico Ingapirca CAI-". Ecuador.

Instituto Nacional de Patrimonio Cultural (s/a). Historia del Proyecto Hojas-Jaboncillo. https://bit.ly/33zcTJW

Jessop, B. (2016) El Estado: pasado, presente y futuro. Ediciones Catarata.

Kingman, E. (2004). Patrimonio, políticas de la memoria e institucionalización de la cultura. Íconos, 20, 26-34. Flacso. https://doi.org/10.17141/iconos.20.2004.66

Marcos, J. (2011). Las investigaciones arqueológicas en los cerros de Hojas y Jaboncillo. En S. Cabrera (Ed.), Patrimonio cultural, memoria local y ciudadanía (pp. 153-169). Corporación Editora Nacional. https://bit.ly/3ftUEI8

Martínez-Valle, L. (2003) Capital social y desarrollo rural. Íconos, 16, 73-83. Flacso. https://doi.org/10.17141/iconos.16.2003.525

Polanyi, K. [2007 (1975)]. La gran transformación. Quipu editorial.

Prats, J. (2004), Gobernabilidad para el desarrollo. Propuesta de un marco conceptual y analítico. En C. Binetti y F. Carrillo-Flórez (Eds.), ¿Democracia 
con desigualdad? Una mirada de Europa hacia América Latina (pp. 3-33). Bogotá, Banco Interamericano de Desarrollo-Comisión Europea. https://bit.ly/3gAd5fB

Lunniss, R. (2011). El Cerro Jaboncillo y el Patrimonio Arqueológico de Manabí. En S. Cabrera (Ed.), Patrimonio cultural, memoria local y ciudadanía (pp. 143-151). Corporación Editora Nacional. https://bit.ly/3gBbK8m

Ragin, C. (2007). La construcción de la investigación social. Siglo del Hombre editores.

Salazar, E. (1994). La Arqueología contemporánea en el Ecuador (1970-1993). Procesos: Revista ecuatoriana de Historia, 5, 5-27. https://bit.ly/34FL9BE

Velecela, M. (2015), Plan integral de gestión del complejo arqueológico de Ingapirca y de sitios asociados. Gráficas Hernández. https://bit.ly/2C8tuZK

Weber, M. (2005) Economía y sociedad. Fondo de Cultura Económica.

Weber, M. (2007) Sociología del poder. Los tipos de dominación. Alianza Madrid.

Fecha de envío: 2020/04/15; Fecha de aceptación: 2020/08/05;

Fecha de publicación: 2020/09/01 